\title{
Political Campaigning: Where Scientific and Ethical Arguments Meet Public Policy
}

\author{
Emily McIvor \\ Science Policy Advisor, People for the Ethical Treatment of Animals \\ (PETA). London, United Kingdom
}

\section{Introduction}

The ambition of the paradigm shift we seek is vast, and the obstacles we face are intractable. For anyone opposing the use of non-human animals (hereinafter referred to as animals) in research and testing, the story has been the same from the start. Legitimate concern for animals has been all-too-easily dismissed as misguided sentimentality, and powerful vested interests have claimed scientific, economic, and moral superiority. But the ground is shifting. Animal researchers accept the need to provide scientific justification for their choices, and the protection of animals is increasingly recognized as a public good. Concern among citizens has been translated into hard-and-fast rules, and scientific advances have added weight to the growing demand for change.

In deciding how best to achieve the paradigm shift, the question for animal advocates is how to create the greatest change in the shortest time possible. This chapter deals with political campaigning at the European Union (EU) level, since the adoption of the first EU Directive on the protection of animals used for scientific purposes, and focuses on the main political developments of the past two decades. Historically, much was made of a perceived choice between presenting ethical or scientific arguments; both are powerful drivers, providing evidence that existing practice is flawed. Other chapters in this Volume describe aspects of those approaches in detail; similarly, the question of whether to focus on the 3 Rs or replacement only is also covered elsewhere. In this chapter, a pragmatic policy focus is necessary to explore how scientific and ethical objectives can be pursued in order to move forward in the political arena, making full use of existing structures and creating new opportunities. The stakes are high. Our vision requires a revolution in science and in the way animals are treated. Twenty-first century technology should not depend on inhumane practices, just as modern economies should not depend on the destruction of the environment or the exploitation of workers.

(C) EMILY MCIVOR, $2019 \mid$ DOI:10.1163/9789004391192_006 
Before proposing future strategies, it is useful to reflect briefly on the current situation. In the EU, Directive 2010/63/EU requires Member States to apply the 3 Rs and encourages the further development of new $3 \mathrm{R}$ methods and techniques. Research funding programs identify the replacement of animal models as scientific and policy objectives; and several publicly funded national centers are now dedicated to developing, validating, and promoting alternative methods. The EU Reference Laboratory for Alternatives to Animal Testing, the European Centre for the Validation of Alternative Methods (EURL-ECVAM) has, among its duties and tasks, the remit to coordinate and promote the development and use of alternatives to procedures in the areas of basic and applied research and regulatory testing (European Parliament, 2010, Directive 2010/63/EU, Annex VII). Each of these achievements has come about because of pressure from citizens and animal advocacy organizations, and each has created a momentum of its own so that further progress is inevitable. At the same time, the number of animals used in scientific procedures in the EU appears to be increasing (Taylor and Rego, 2016); and animal use is robustly defended by powerful commercial, academic, and charitable organizations. It is legal to restrain conscious non-human primates (NHPs), so they are unable to move at all for long periods, and to poison animals to death by applying toxic chemicals to their skin. The scientific revolution is undoubtedly underway, and Directive 2010/63/EU identifies animal welfare as a "value of the Union" (European Parliament, 2010, Recital 2); but current practice has not caught up.

The development of current European regulatory frameworks can be seen as the culmination of a series of historical confrontations between animal users and advocates (Lyons, 2011). By identifying five "critical junctures", including the adoption of the United Kingdom's Cruelty to Animals Act in 1876, the Royal Commission of 1912, and the adoption of the Animals (Scientific Procedures) Act in 1986 (UK's transposition of Directive 1986/609 EEC; Council of the European Communities, 1986), Lyons (2011) traces the evolution, from a largely self-regulating, animal user community to the current regulatory regime. The relevance to our situation is the analysis of power exercised by those who defend animal use. Through early critical junctures, the power to decide whether animal use is justified, to control access to information, and to entrench an establishment view that the use of animals is essential to medical progress, was 
firmly placed in the hands of animal users. Only later, with adoption of the 1986 Act, did the necessity for greater public and political scrutiny gain broad support.

Lyons describes key elements of various positions held, including this analysis of an animal use ideology (2011, pp. 360-361):

- It claims that animal welfare is secondary to research goals

- It considers animal experimentation necessary, and hence permissible, in the pursuit of knowledge without immediate or foreseeable human benefit

- It is opposed to utilitarian scrutiny of experimentation proposals

- It supports professional self-regulation and opposes lay interference in animal experimentation.

This is contrasted with an animal welfare belief system:

- It believes that animal welfare should be given significant weight in policy making

- It believes that proposals for harmful uses of animals should be subject to independent utilitarian analysis

- It considers animal experimentation necessary, and hence permissible, only to satisfy urgent and pressing human needs

- It supports the requirement of lay control to ensure consideration of wider public and animal interests.

And an animal rights philosophy:

- It posits that all sentient animals have inherent value and share human interest in avoiding suffering

- It claims that the fundamental rights of protection from torture, killing, and enslavement should, therefore, extend beyond the human species to other sentient animals

- It argues for the abolition of animal experimentation.

In the political arena, the welfare belief system often achieves consensus, and politicians can usually gain majority support for measures appearing to balance competing interests. Furthermore, a welfare agenda represents valuable middle-ground when the positions of different interest groups seem so far apart as to be irreconcilable.

Efforts to create a level playing field between industry and civil society groups have proved effective at the Eu level (Persson, 2007); but in terms of numbers alone, leaving aside financial resources, industry and animal user groups are better represented than animal advocacy organizations. The UK Home Office public consultation on the European Commission's (EC) proposal to revise Directive 86/6og/EEC received only 19 responses from animal 
welfare organizations out of a total of 87 submissions, including 33 from academic institutions and 17 from representative bodies (Home Office, 2010). An associated imbalance, concerning access to scientific and political decision makers (Lyons, 2011), again risks leaving animal advocacy organizations severely outdone. However, public opinion is also an important element of the debate, and animal advocacy organizations have been effective in demonstrating that public concern for animals must be taken into consideration.

Polling commissioned by the European Coalition to End Animal Experiments (ECEAE) on the revision of Directive 86/6og/EEC - conducted by YouGov (2009) in the UK, France, Germany, Italy, Sweden and the Czech Republic - found that public opinion was not consistent with the EC's legislative proposal; for example, substantial majorities in all countries surveyed favored a ban on experiments causing pain or suffering to NHPs (House of Lords, 2009). UK Government surveys exploring attitudes to animal research (Clemence and Leaman, 2016; Leaman, Latter and Clemence, 2014) note varying degrees of public support or opposition, depending on the phrasing of questions. There was a slight increase, between 2014 and 2016, in respondents who supported a ban on the use of any animals in research, from $23 \%$ to $26 \%$. The 2016 survey also found that $59 \%$ of people disagreed with the statement "it does not bother me if animals are used in scientific research", showing concern for animals among a clear majority of respondents. The difference, in policy terms, between the abolitionist view (represented by the UK's $26 \%$ ) and a gradualist approach is significant; but there is strong agreement ( $74 \%$ of respondents) with the statement that more work is needed on alternatives to using animals in scientific research.

In terms of the wider political debate, even though detailed discussions about animal care and use tend to emphasize differences among stakeholder organizations rather than areas of agreement, promoting the replacement of animal procedures is compatible with all three of the belief systems identified above. Arguing for the increased uptake of human biology-based technologies in biomedical research is not new; but in an era of rapidly developing science and divergent opinion concerning other aspects of the debate, its importance cannot be overestimated. Because of the need for policy makers to arbitrate between opposing views, and the broad appeal of the alternatives' message, a major benefit of effective political lobbying is, therefore, ensuring that the replacement of animal procedures is promoted to the greatest extent possible. This cannot come at the expense of trying to improve conditions for the animals that are used, but it is a powerful driver towards achieving the paradigm shift. 
The adoption of EU legislation provides multiple access points, and the EC encourages interest group participation in order to meet the objective of connecting the EU more closely to citizens (Persson, 2007). This objective was amply demonstrated during the lengthy process through which Directive 1986/609/EEC was revised and Directive 2010/63/EU came into being. While the revision was underway, the EC adopted an Interinstitutional Agreement on Better Law-making (European Commission, 2003, 2003/C321/01), strengthening pre-legislative consultation processes and requiring impact assessments. These access points, while often appearing to delay the process, ensured valuable evidence was gathered, informing both the legislative proposal and further political negotiations. Studies, including the scientific Opinion by the European Food Safety Authority's Animal Health and Animal Welfare Panel (AHAW), and findings from the Technical Expert Working Group convened by the EC, created useful evidence and opportunities for further interventions the following years.

The legislative proposal — when finally published in 2008-irritated those defending animal use and, although representing a considerable improvement on previous legislation, it also failed to satisfy animal advocates. The U $\mathrm{K}$ animal user community, coming together under the auspices of joint Bioscience Sector position papers, identified several areas of concern, including the proposal to protect certain invertebrate species, limits on use of NHPs, and burdensome bureaucracy. The organizations also raised concerns that the draft Directive would undermine UK and European competitiveness, noting that "As well as problems with the content, the wording throughout the Directive requires significant review for scientific accuracy and internal consistency" (Bioscience Sector, 2009, p. 2). While generally supporting the application of the ${ }_{3} \mathrm{Rs}$, the groups opposed creation of national structures to assist in the validation of new $3 \mathrm{R}$ methods, claiming that: "The proposals for National Reference Laboratories are unnecessary and infeasible and would not be effective at developing alternative methods. They would divert research funding away from research which might not only develop alternatives but further benefit biomedical discoveries" (Bioscience Sector, 2009, p. 39).

But by the end of the political negotiation, the new legislation, Directive 2010/63/EU, included a handful of promising elements, alongside several measures that are weaker in terms of animal protection, than those contained in the EC's original proposal. Central to the achievements for animal protection lobbyists is Recital 10 (European Parliament, 2010), which specifies that "this Directive represents an important step towards achieving the final goal of full 
replacement of procedures on live animals for scientific and educational purposes as soon as it is scientifically possible to do so." In response to proactive EU-wide campaigning for greater prominence to the replacement of animal experiments and for the inclusion of basic and applied animal research in the remit of EURL ECVAM, EU Member States are now required to promote development and use of alternatives, establish a single contact point to receive information about new methods, join an EU-wide network of contact points, and require new projects to be authorized only when alternatives have been considered. Campaigns to ensure regular "thematic reviews" on areas, such as the replacement of experiments on NHPs, were partially successful (Article 58 ); and Recital 10 states that the Directive should be "reviewed regularly in light of evolving science and animal protection measures" (European Parliament, 2010). Emphasis on the use of existing alternative techniques and the further development of new methods is strengthened by requirements for project evaluations, increased transparency, and, most importantly, the retrospective assessment of all projects using NHPs and projects involving procedures classified as "severe" (Article 39).

\section{Ending Cosmetics Animal Testing: 20 Years and Counting...}

Nowhere is the importance of procedural access points and the willingness of legislators to respond to the wishes of citizens more visibly demonstrated than in the 20-year struggle to end animal testing of cosmetics and the sale of newly animal-tested cosmetics ingredients in the $\mathrm{EU}$. Without detailing every one of the (numerous) twists and turns it took to see the 2013 ban enter into force, one hard-fought measure deserves special mention: the requirement for a full political negotiation in the event of any attempt to delay implementation of the final 2013 deadline. Although the sale ban had been agreed on in 1993 and was due to be implemented in 1998, the EC was permitted, under the 6th Amendment to the Cosmetics Directive (European Commission, 1993), to delay it until 2000 and then to 2002, on the grounds that replacement tests were not fully developed. The delays were agreed on through the comitology process, offering a lower level of access than a full political debate. However, further delays were not permitted beyond the 2002 deadline, by which time a new legislative proposal was published, triggering a full political negotiation before further delays could be adopted.

The point of interest for campaigners is that within the $7^{\text {th }}$ Amendment (European Commission, 2003), new wording deliberately prevented any further delay without a legislative proposal being debated and voted upon by the European Parliament and Council. The 2009 phase of the sale ban gave no 
provision for any kind of delay, on any grounds; and the final 2013 phase could only be delayed by new legislation. Creating the requirement for another access point - a 2013 renegotiation in the event that animal tests had not been replaced - was the key compromise that satisfied both industry and animal advocates. As the 2013 deadline approached, the EC opted to implement the ban and avoid any further accusations that they were ignoring the wishes of citizens. However, nothing is safe until full animal replacement is achieved, and although animal organizations rightly view an end to cosmetics animal testing as a political objective, achievable in the absence of alternatives being in place, loopholes putting our achievements at risk are relatively easily disguised. Perceived ambiguities concerning the terms of the ban have led to legal challenges, underlining the need for constant vigilance. Had the wording of Article 13 of the Cosmetics Directive been tighter (European Commission, 2009, Regulation (EC)1223/2009), we could have avoided the threat of further challenges.

On the day the European Parliament's Environment Committee debated their second reading position, a front-page article in the UK's Independent newspaper revealed behind-the-scenes lobbying by a major company to ensure ambiguity persisted, and loopholes were not closed (Woolf, 2002). The article was handed to Members of the European Parliament (MEPs) and while some unhelpful caveats remained, the final wording saw the Parliament successfully overcome opposition from EU Member States and adopt measures that would ban animal testing for cosmetics, and phase in the ban on selling newly animal-tested cosmetics ingredients (Osborn, 2002). The cosmetics campaign and resulting legislation also emphasize the importance of consensusbuilding around the need to replace animal tests. The 1993 legislation triggered increased efforts to replace animal methods and resulted in valuable contributions from industry, Member States, and the EC. EURL ECVAM became a worldleader in validating alternatives, and the EU entered the twenty-first century expressing a clear aspiration to replace outdated, failing animal methods.

The political negotiation of Registration, Evaluation, Authorisation and Restriction of Chemicals (REACH), the EU Chemicals Regulation (European Commission, 2006, Regulation (EC) 1907/2006), forced stakeholders with different aims to work together. A direct confrontation between industry (who favored lower costs and regulatory burdens) and environmental groups (who called for expensive animal testing and rigorous regulatory processes) left animal advocates needing to tread carefully. However, the animal protection agenda 
was in no danger of being ignored. Calculations regarding the number of animal tests that could be required by REACH—varying initially from 9.5 million to 45.8 million (Institute for Environment and Health, 2001) - hit the headlines; but there was an associated danger of animal welfare arguments being co-opted by those simply wanting to reduce test costs. Politicians, more likely to favor environmental concerns, were also those with the strongest policies on animal protection; so a simple alignment with industry would have been highly problematic. Policies on data-sharing and transparency helped to forge links between animal and environmental groups, but the most important development concerned the recognition that animal tests represented outdated science. As the discussions progressed, all players acknowledged that because the future EU chemicals policy would be dependent on animal testing, it was impossible to ignore either the animal welfare or scientific case for replacement.

Between 2001 and 2003 the tone of the European debate around toxicity testing shifted. Publication of the ECEAE report, The Way Forward: A NonAnimal Testing Strategy for Chemicals (European Coalition to End Animal Experiments, 2003) was pivotal in defining the debate for decades to come. The ECEAE argued that in an ideal situation, there would be no need to make a choice between saving animals and protecting people. Replacing animal tests provided a win/win solution. New non-animal tests could be better, cheaper, and faster; and reliance on outdated animal tests would waste money and potentially confound those seeking decisive regulatory action. The conclusion of the REACH negotiation in 2006 saw several meaningful animal welfare demands enshrined in legislation, with "promotion of alternative methods for assessment of hazards of substances" becoming one of three objectives of the legislation, listed in Article 1.

The political shift, which started with tentative statements from radical Green Party politicians about the scientific need to replace animal tests, grew to represent the mainstream view of the European Parliament and Council. By the time MEPs of the center left had picked up the new rhetoric, a convincing case had been made, and at first reading the European Parliament's environmental committee voted for an entirely non-animal testing approach under REACH (Committee on the Environment, Public Health and Food Safety, 2005), marking a significant call on all concerned to do more to replace animal tests. Again, consensus around the need to replace animal methods achieved overwhelming support, and a central requirement of REACH is that animal testing should only be carried out as a last resort.

The legislative gains enshrined in REACH built on past success concerning replacement, including the application and development of ${ }_{3} \mathrm{R}$ methods, as mentioned in Directive 1986/6og/EEC and required by the 1993 Cosmetics 
Directive, and broke new ground by requiring rapid updating of legislation in response to new methods becoming available. What these legal requirements did not do was ensure that regulators and the European Chemicals Agency (ECHA) apply the rules without constant pressure from campaigners, culminating in several rulings against ECHA by the EU Ombudsman for failing to meet regulatory requirements relating to avoidance of animal testing (PETA UK, 2014; ECHA, 2015). 2001-2003: Paradigm Shift Meets Parliament

The fifth term of the European Parliament (1999-2004) saw MEPs from across the political divide join forces to push the replacement agenda through legislative debates, Reports and Parliamentary Questions. The fact that REACH and the 7th Amendment to the Cosmetics Directive were on the Parliamentary agenda at the same time, and the EC was working to revise Directive 1986/6o9/EEC, made for more urgency. The EC/Industry collaboration, the European Partnership for Alternatives to Animal Testing (EPAA), was established during this period, providing a forum in which companies could combine resources and expertise and demonstrate their commitment to implementation of the 3 Rs. The EPAA has achieved a number of notable successes, including the study that informed changes to Annex VIII of REACH, ensuring that acute toxicity studies, using the dermal route, can be waived in most circumstances (EPAA, 2014).

In the midst of these political activities, the need for an accelerated process to achieve international adoption of the Organisation for Economic Co-operation and Development (OECD) Test Guidelines was recognized. The International Coalition for Animal Protection in OECD Programs (ICAPO) was formed (ICAPO, n.d.), allowing scientific experts working for international animal protection organizations, to participate in global efforts to implement the ${ }_{3}$ Rs. The structure of ICAPO has, helpfully, required organizations to maintain a single point of contact with the OECD and to collaborate with each other. To complete the picture, EU Framework Program (FP) funding decisions were taking a positive direction. Under FP6 (2002-2006), 21 projects to advance animal-free methods were funded, with a total of over $€ 63$ million, and contained wording - thanks to the European Parliamentconcerning the need to replace toxicity testing on animals (European Parliament, 2002, Decision 1513/2002/EC). In this context, during the first years of the twenty-first century, several advances were made, the results of which are still playing out. 
During the negotiation of Directive 2010/63/EU, information about the intentions of industry and the animal user community crept into the public domain. In the absence of replacement science successfully displacing animal research, the future for animals could look very bleak indeed. In 2009, the UK House of Lords Select Committee on the European Union SubCommittee D (Environment and Agriculture) held an inquiry and reported to Parliament (HL 164 2009-2010). During the evidence sessions, questions were posed about the potential for higher welfare standards in the $\mathrm{EU}$ to drive animal use abroad. While there was clear evidence that an EU research base holds several advantages for companies, several contributions were worrying.

Evidence presented in the Memorandum by the Bioscience Sector (House of Lords, 2009) notes the existence of "substantial competition from countries, such as China, India, and Singapore in developing infrastructure to undertake animal research, which includes not just routine toxicity tests but also R \& D" (p. 21); and states that "commercial investment [is] increasing faster in countries outside the EU, such as the Us, China and India" (p. 19). During the oral evidence session, industry representatives described the experience that "most major pharmaceutical companies are now investing in Asia" (p. 43), with decisions being "influenced very strongly, particularly, by access to non-human primates and developing the Asian market with particular reference to China" (p. 43). One representative went on to describe new facilities in Shanghai, which will focus on cancer research and collaboration with a Chinese institution dedicated to constructing a specific NHP facility.

The view that higher EU welfare standards are unlikely to contribute in the short term to this shift is broadly supported, but the expectation of industry is that growing markets and longer-term projections are contributing to the expansion of animal facilities in countries not governed by EU standards. The fear is not so much that companies will fail to keep pace with, for example, EU standards of housing and care, but that in countries with less rigorous legislation, less attention will be paid to severity limits, reporting, and transparency. This global expansion does not, however, mean that EU political campaigning is any less important. Increased scientific scrutiny, such as that required by European legislation, along with funding for the development of alternatives, is driving global change. We cannot protect NHP in Chinese research facilities, but we can hold the science behind NHP use to account. 
Use of NHPS in the EU is highly controversial. Years of public campaigning has raised awareness of NHP suffering and sentience (Jennings, 2010); and the 2007 European Parliamentary Declaration, which called for a timetable for replacing all use of NHPs (European Parliament, 2007, P6_TA(2007)0407) led to the inclusion of proposals to limit N HP use in the EC's legislative proposal of 2008. Alongside this, the EC requested a series of Opinions from its scientific committees concerning the potential to replace NHP use.

Animal advocates have, repeatedly, found the process by which the Opinions have been formulated frustrating and biased. Contributors tend to be NHP users rather than biomedical researchers who use non-animal methods. In the most recent Opinion, released by the Scientific Committee on Health Environmental and Emerging Risks (SCHEER) (SCHEER, 2017), the Committee argues in favor of continued NHP use, while failing to acknowledge key reviews on the ineffectiveness of NHPS as a model for humans or reviews on advances in alternative animal-free methods. Nevertheless, the Committee made a handful of recommendations, including that systematic reviews should be undertaken and the "psychological effect" on N HPs should be better assessed (though this latter recommendation could lead to further research on NHP laboratory welfare).

In this context, it is not hard to see why campaigners have continued to call for an outright ban on all animal experiments. The Lisbon Treaty of 2009 introduced a process by which European citizens can initiate activity by the EC, including proposals for new legislation, if a petition receives one million signatures collected in seven EU Member States within one year (the European Citizens' Initiative, European Commission, 2011). The third successful Citizens' Initiative, Stop Vivisection, registered in 2012, called on the EC to "abrogate directive 2010/63/EU on the protection of animals used for scientific purposes and to present a new proposal that does away with animal experimentation and instead makes compulsory the use-in biomedical and toxicological research — of data directly relevant for the human species" (European Citizens' Initiative, 2016). The Citizens' Initiative demonstrated, again, EU-wide support for ending the use of animals in research and testing, raised awareness among policy makers, and generated new commitments from the EC. The European Parliament hearing on the Citizens' Initiative gave ME Ps the opportunity to listen to arguments first-hand and question experts (European Parliament, 2015). 
The EC's 2015 Communication responding to Stop Vivisection (C(2015) 3773) identified four action points:

(1) Acceleration of progress in the 3 Rs through knowledge sharing

(2) Development, validation, and implementation of new alternative approaches

(3) Enforcement of compliance with the 3 Rs principle and alignment of relevant sector legislation

(4) Engagement in a dialogue with the scientific community.

The EC's response concluded by welcoming "the mobilisation of citizens in support of animal welfare" stating that "the Citizens' Initiative has provided an opportunity to critically examine how the EU can reinforce its efforts in moving from animal to non-animal based research and testing" (European Commission, 2015, p. 10). However, there is no evidence that relevant decisionmaking bodies, such as Member State National Committees, referred to in Directive $2010 / 63 / \mathrm{EU}$, are making the necessary adjustments.

Action 4 committed the EC to organize a scientific conference titled NonAnimal Approaches - The Way Forward, which, although supported by a wider-than-usual audience of stakeholders, was boycotted by the organizers of the Stop Vivisection Citizens' Initiative, who later made a complaint to the Eu Ombudsman, considering that "the [European] Commission had given an inadequate response to the initiative and the detailed proposals put forward in the context of the initiative". The Ombudsman rejected the complaint (EU Ombudsman, 2017); but the substance of the Initiative remains active, and is an important milestone for policy makers at all levels of EU decision making.

Scientific progress does not necessarily equate to changes in practice, in public policy, or in legislation; but political progress can drive science. For this reason alone, effective political strategies are essential. The paradigm shift can be accelerated by improvements in transparency, reporting, and protection of animals as well as by increasing levels of scientific scrutiny, funding, and political will. Experience gained at the Eu level demonstrates that when public opinion-backed by convincing evidence and practical proposals — can be effectively presented, policy makers are required to balance competing interests and promote workable solutions. In the field of research on animals, this often results in increased efforts to replace animal experiments. Public opinion surveys indicate that legislators have not yet created laws that adequately address citizens' concerns; but continuing public and political pressure has ensured 
new initiatives are likely and further access points, in terms of influencing the regulatory agenda, are open to advocacy groups.

Developing a coherent political strategy on the basis of either science or animal protection alone is fraught with difficulties. Heated debate, and regulatory systems attempting to balance animal suffering with expected outcomes have forced animal advocates into the scientific arena and scientists to respond to welfare requirements. Those campaigning for a paradigm shift are gaining scientific weight and credibility, and new technologies are unstoppable.

So, what will end the use of animals in experiments in the shortest possible time? Using the experience gained over the past twenty years of EU-level campaigning, it seems sensible to accept that widely different approaches and organizations all have their place. Welfare advocates who work only with industry can achieve a great deal; the promoters of the Citizens' Initiative, Stop Vivisection, caused the EC to set new goals and attempt to create consensus between stakeholders holding radically different views, and EU-level coalitions of national advocacy groups, together with a handful of international organizations, through dogged scrutiny of implementation procedures, maintain public and political pressure. The need for legislators and regulators to demonstrate a willingness to hear the views of a range of stakeholders has allowed animal advocates to find a voice at all levels of political processes and to work with other campaign groups, industry, and academia to promote shared objectives.

The experience of political campaigning described above is offered in the hope that the paradigm shift happens sooner rather than later. The following overview of the points described above and lessons learned may also be of use:

\section{Political Campaigning:}

- Make use of all procedural access points, remembering that early intervention works best.

- Work across political divides and with all stakeholders to understand the full range of opinions and differing viewpoints.

- Join expert groups, share expertise, and try to avoid duplicating the work of other, similar organizations.

- Understand the agenda of your opponents and check the meaning of wording that seems unclear. Loopholes can be avoided if spotted early enough.

- Create new access points. Always work for regular reviews, reports, and further studies.

- Find ways to increase transparency. From ensuring all animals are counted to sophisticated prospective and retrospective reviews, transparency is essential. 
- Appreciate the work of consensus-based entities. Where there is consensus, meaningful progress should be achievable.

\section{Amplifying Our Message:}

- Animal advocacy organizations working together are more likely to succeed. We have seen this through ICAPO and in the political arena. Sharing material early on and avoiding duplication is more likely to ensure initiatives are successful.

- Formulating joint positions with other organizations, such as environment, health, patient, and industry groups, amplifies our message.

- Coalitions and umbrella groups are helpful but need to demonstrate the extent of their supporter base, for example, by directly linking politicians with national organizations and the citizens they represent.

The question of global versus national or regional campaigning answers itself. We need to work at every level, in every forum, using all peaceful, evidencebased, effective means available to us. From handing out leaflets in the street to funding studies by researchers to expose failing animal models of disease, every contribution is valuable and is helping to achieve the paradigm shift.

\section{References}

Bioscience Sector (2009). A Bioscience Sector Response to the House of Lords European Union Committee Inquiry: Revision of Directive 86/6og on the Protection of Animals Used for Scientific Purposes. [online] Available at: https:/wellcome.ac.uk/sites/ default/files/wtx055911.pdf [Accessed 15 June 2017].

Clemence, M. and J. Leaman (2016). Public Attitudes to Animal Research in 2016. A report by Ipsos MORI for the Department for Business, Energy \& Industrial Strategy, Ipsos MORI Social Research Institute. [online] Available at: https://www .ipsos.com/sites/default/files/publication/1970-01/sri-public-attitudes-to-animalresearch-2016.pdf [Accessed 15June 2017].

Committee on the Environment, Public Health and Food Safety (2005). Report on the Proposalfora Regulation of the European Parliamentand of the Councilon the Registration, Evaluation, Authorisation and Restriction of Chemicals (REACH), Establishing a European Chemicals Agency and Amending Directive 1999/45/EC and Regulation (EC) on Persistent Organic Pollutants. (2003/0256(COD)). [online] Available at: http:// www.europarl.europa.eu/sides/getDoc.do?pubRef=-//EP//TEXT\%2oREPORT\% 20A6-2005-0315\%200\%20NOT\%20XML\%2oVo//en [Accessed July 212017 ].

Council of the European Communities (1986). Council Directive 86/6og/EEC of 24 November 1986 on the Approximation of Laws, Regulations and Administrative 
Provisions of the Member States Regarding the Protection of Animals Used for Experimental and Other Scientific Purposes. Official Journal of the European Communities, L 358, pp. 1-28.

ECHA (2015). ECHA's Approach on Avoiding Unnecessary Animal Testing, 4oth Meeting of the Management Board 16-17 December 2015 [online] Available at: https:// echa.europa.eu/documents/10162/1564405/mb_54_2015_avoiding_testing_en.pdf/ c3oe5eof-0299-4078-9301-67e402e28257 [Accessed 10 August 2018].

EPAA (2014). European Partnership for Alternatives to Animal Testing: Achievements. [online] Available at: https://circabc.europa.eu/sd/a/17b2b74c-015a-495f-ba7f -bb549335efd3/Achievements\%2010\%2oyears\%2oEPAA.pdf [Accessed 17 October 2018].

European Citizens' Initiative (2016). Stop Vivisection. [online] Available at: http://www .stopvivisection.eu [Accessed 21 July 2017].

European Coalition to End Animal Experiments (2003). The Way Forward: A NonAnimal Testing Strategy for Chemicals. [online] http://www.eceae.org/_lib/ userfiles/files/Downloads/ECEAE_TheWayForward_part1.pdf [Accessed 10 August 2018].

European Commission (1993). Council Directive 93/35/EEC of14 June 1993 Amending, for the Sixth Time, Directive 76/768/EEC on the Approximation of the Laws of the Member States Relating to Cosmetic Products. Official Journal of the European Communities, L151, 23/o6/1993, pp. 32-37.

European Commission (2003). Interinstitutional Agreement Between the European Parliament, the Council of the European Union and the European Commission on Better Law-making. Official Journal of the European Union, $\mathrm{C}_{321}$, pp. 1-5.

European Commission (2006). Regulation (EC) 1907/2006 of the European Parliament and of the Council of 18 December 2006 concerning the Registration, Evaluation, Authorisation, and Restriction of Chemicals (REACH), Establishing a European Chemicals Agency. Official Journal of the European Communities, L396, pp. $1-849$.

European Commission (2009). Regulation (EC) 1223/2009 of the European Parliament and of the Council of 30 November 2009 on Cosmetic Products. Official Journal of the European Union, L 342, 22.12.2009, pp. 59-209. [online] Available at: https://eurlex.europa.eu/legal-content/EN/TXT/PDF/?uri=CELEX:32009R1223\&from=EN [Accessed 21 April 2018].

European Commission (2011). Regulation of the European Parliament and of the Council of February 16, 2011 on the Citizens' Initiative. Official Journal of the European Union, L 65, pp. 1-22.

European Commission (2015). Communication from the Commission on the European Citizens' Initiative "Stop Vivisection". [online] Available at: http://ec.europa .eu/transparency/regdoc/rep/3/2015/EN/3-2015-3773-EN-F1-1.PDF [Accessed 15 June 2017]. 
European Ombudsman (2017). Decision in Case 1609/2016/JAS on the European Commission's Response and Follow-up to the European Citizens' Initiative "Stop Vivisection." [online] Available at: https://www.ombudsman.europa.eu/en/cases/decision .faces/en/78182/html.bookmark [Accessed 15 June 2017].

European Parliament (2002). Decision 1513/2002/EC of the European Parliament and of the Council of 27 June 2002, Concerning the Sixth Framework Program of the European Community for Research, Technological Development and Demonstration Activities, Contributing to the Creation of the European Research Area and to Innovation (2002 to 2006). Official Journal of the European Communities, L232, pp. 1-33. [online] Available at: https://publications.europa.eu/en/publication -detail/-/publication/5ao16937-b81d-41ca-aac5-1b5bedd26f46/language-en [Accessed 15 August 2018].

European Parliament (2007). Declaration of the European Parliament on the Use of Primates in Scientific Experiments. P6_TA(2007)0407: Plenary Session (23/04/2007). [online] Available at http://www.europarl.europa.eu/sides/getDoc.do?reference= P6_TA(2007)0407\&language=EN [Accessed April 8 2018].

European Parliament (2015). Stop Vivisection: European Citizens' Initiative Public Hearing. [online] Available at: http://www.europarl.europa.eu/committees/en/envi/ events-citizint.html?id=20150424CHEoo301 [Accessed 15 June 2017].

European Parliament (2010). Directive 2010/63/EU of the European Parliament and of the Council of 22 September 2010 on the Protection of Animals Used for Scientific Purposes. Official Journal of the European Communities, L276, pp. 33-79. Available at: http://eur-lex.europa.eu/legal-content/EN/TXT/?uri=CELEX:32010Loo63 [Accessed 15June 2017].

Home Office (2010). Summary of Responses to the Consultation on Proposals for the Revision of EU Directive 86/6og/EEC on the Protection of Animals Used for Scientific Purposes. [online] Available at: http://webarchive.nationalarchives. gov.uk/20100408171921/http://scienceandresearch.homeoffice.gov.uk/animal $\% 2$ Dresearch/legislation/summary-report2835.pdf?view=Binary [Accessed 20 July 2017].

House of Lords Select Committee on the European Union Sub-Committee D (Environment and Agriculture) (2009). The Revision of the EU Directive on the Protection of Animals Used for Scientific Purposes. Volume II, Evidence. [online] Available at:https://publications.parliament.uk/pa/ld200809/ldselect/ldeucom/164/164ii .pdf [Accessed 22 July 2017].

ICAPO (n.d.). About. [online] Available at: https://www.icapo.org/about [Accessed 21 July 2017].

Institute for Environment and Health (2001). Testing Requirements for Proposals under the Ec White Paper "Strategy for a Future Chemicals Policy". Leicester, Uk: Institute for Environment and Health. [online] Web Report W6. Available at: http://www 
.iehconsulting.co.uk/IEH_Consulting/IEHCPubs/HumExpRiskAssess/w6.pdf [Accessed 15 August 2018].

Jennings, M. (2010). Special Protection for Primates - The Need for Faster Progress. Alternatives to Animal Experimentation, 27, Special Issue.

Leaman, J., J. Latter and M. Clemence (2014). Attitudes to Animal Research in 2014. A report by Ipsos MORI for the Department for Business Innovation \& Skills. Ipsos MORI Social Research Institute. [online] Available at: https://www.ipsos .com/sites/default/files/migrations/en-uk/files/Assets/Docs/Polls/sri_BISanimal research_NONTRENDreport.pdf [Accessed 30 July 2018].

Lyons, D. (2011). Protecting Animals Versus the Pursuit of Knowledge: The Evolution of the British Animal Research Policy Process. Society \& Animals, 19, pp. 356-367.

Osborn, A. (2002). Cosmetics Tested on Animals to Be Banned. The Guardian. [online] Available at: https://www.theguardian.com/uk/2002/nov/08/animalwelfare.eu [Accessed 21 July 2017].

Persson, T. (2007). Democratizing European Chemicals Policy: Do Consultations Favour Civil Society Participation? Journal of Civil Society, 3(3), pp. 223-238.

PETA UK (2014). European Ombudsman Ruling on PETA Complaint a Victory for Animals Used in EU Chemical Tests. [online] Available at: https://www.peta.org.uk/ blog/official-ruling-must-done-minimise-cruel-chemical-tests-animals-europe/ [Accessed 10 August 2018].

SCHEER (2017). Final Opinion on the Need for Non-human Primates in Biomedical Research, Production and Testing of Products and Devices (update 2017). [online] Available at: http://ec.europa.eu/environment/chemicals/lab_animals/pdf/ Scheer_may2017.pdf [Accessed 13 August 2018].

Taylor, K., and L. Rego (2016). EU Statistics on Animal Experiments for 2014. Alternatives to Animal Experimentation, 33(4), pp. 465-468.

Woolf, M. (2002). Cosmetics Company Memo Reveals Plan to Sidestep EU Animal Testing Ban. The Independent. [online] Available at: http://www.independent.co.uk/ news/world/europe/cosmetics-company-memo-reveals-plan-to-sidestep-euanimal-testing-ban-133147.html [Accessed 21 July 2017]. 